\section{GRACE and Water Loss from Indo-Ganga Basin}

The Gravity Recovery and Climate Experiment (GRACE) uses satellite based estimates to assess depletion in groundwater from gravity anomalies. The GRACE technique attempts to quantify variations in Terrestrial Water Storage (TWS) which is the cumulative effect of components like groundwater, surface water, soil moisture, snow and ice, biomass apart from several other influences. Separation of groundwater from other components, therefore, need in situ observations and land surface/ hydrological modeling which is highly data dependent exercise. However, reliability of information derived on earth resources from any kind of remote sensing data depends on how best it tallies with ground reality. The sensitivity of satellite based gravity studies is quite high.

Based on GRACE, scientists have computed an annual water loss of $54 \mathrm{~km}^{3}$ in the Indo-Ganga basin and an overall $10 \mathrm{~cm} / \mathrm{yr}$ fall of water table across the region. It has been assumed that the total mass loss (changes in TWS) has been exclusively due to groundwater loss from the region (IndoGanga Basin). However, the GRACE Projection does not match with ground reality in the region. According to Central Ground Water Board the premier groundwater organization in India, IndoGanga basin except in the northwestern and western fringe areas (Rajasthan, Punjab, Haryana and Delhi), is not overexploited and has sufficient surplus resource to support development (as per latest data, 2009). Exploitation of groundwater in the region is on without any adverse effects. This has left question mark on the efficacy of GRACE as a monitoring tool in India.

Contrasting results of GRACE output may be due to several reasons:

1. GRACE technique has too low a resolution (scale: $250 \mathrm{~km}$ radius) to be a viable monitoring tool for groundwater resource in India, whereas Central Ground Water Board and State Ground Water Organisations have a well-built network of monitoring system (partly automated) across the country which is yielding historical water level and quality data on groundwater resource of India.

2. Gravitational data get sparser as the area examined gets smaller, and in areas smaller than 75,000 square miles it gets more difficult to reach conclusions about groundwater supplies. Most aquifers are smaller than that and this is a major limitation of GRACE predictions.

3. The gravity anomalies may not necessarily be solely due to groundwater loss, but due to various other geological factors, which need to be understood.

4. Study of soil moisture storage and its contribution to groundwater from both small and big reservoirs, and canal system, besides substantial infiltration (20-45\%) from applied irrigation which in turn depend on soil properties, initial moisture content of the profile are the necessities in the computation.

Though GRACE has yielded good results in USA, its application in Indian context having very different hydrogeological set up, climate and rainfall pattern, land use, soil conditions, crops, water use patterns etc has to be further confirmed.

GRACE in the present form is liable to yield unreliable results on account of its low spatial resolution and complications introduced by contributions from other sources of water and various other factors.

- Editor 